\title{
When the going gets rough: a sequela of splenic trauma
}

\author{
Christine Azzopardi, ${ }^{1}$ Joseph Attard, ${ }^{2}$ Sarah Aquilina, ${ }^{1}$ Reuben Grech ${ }^{1}$
}

${ }^{1}$ Department of Radiology, Mater Dei Hospital, Msida, Malta

${ }^{2}$ Mater Dei Hospital Malta, Msida, Malta

Correspondence to Dr Christine Azzopardi, chrissyazz@yahoo.com

Accepted 30 October 2014

\section{DESCRIPTION}

\section{Case report}

A 45-year-old man presented with left-sided flank pain 2 days after a rough game of football. On examination, extensive bruising was evident over his left chest wall. His vital parameters were stable with a blood pressure reading of $129 / 85 \mathrm{~mm} \mathrm{Hg}$ and a slight tachycardia of $105 \mathrm{bpm}$. He was exquisitely tender over the left seventh to nineth ribs. Rib fractures were confirmed on plain radiography and an ultrasound of the abdomen was performed to exclude any underlying visceral injury.

An abdominal ultrasound demonstrated free intra-abdominal fluid. A $1.5 \mathrm{~cm}$ round, hypoechoic lesion was present within the spleen. On colour Doppler examination bidirectional internal flow was observed with the typical 'Yin-Yang' sign consistent with a pseudoaneurysm (figure 1).

A contrast-enhanced abdominal CT scan in the arterial phase was subsequently performed. This showed a subcapsular splenic haematoma involving the lower pole of the spleen and a splenic laceration with an intraparenchymal pseudoaneurysm (figure 2). No active extravasation was observed on delayed sequences. The pancreas did not show any signs of fat stranding or oedema, making pancreatitis unlikely. This was supported by a normal amylase level, making trauma the most likely cause for pseudoaneurysm formation in this case.

Selective splenic artery angiography was performed, confirming the pseudoaneurysm with subselective cannulation of the two feeding vessels. The latter were occluded using microcoils (figure 3 ).

\section{DISCUSSION}

The spleen is the most commonly injured intra-abdominal organ following trauma; contrast-enhanced CT is the imaging modality of choice in stable patients with blunt abdominal trauma. ${ }^{1}$ The risk of rupture of a splenic artery

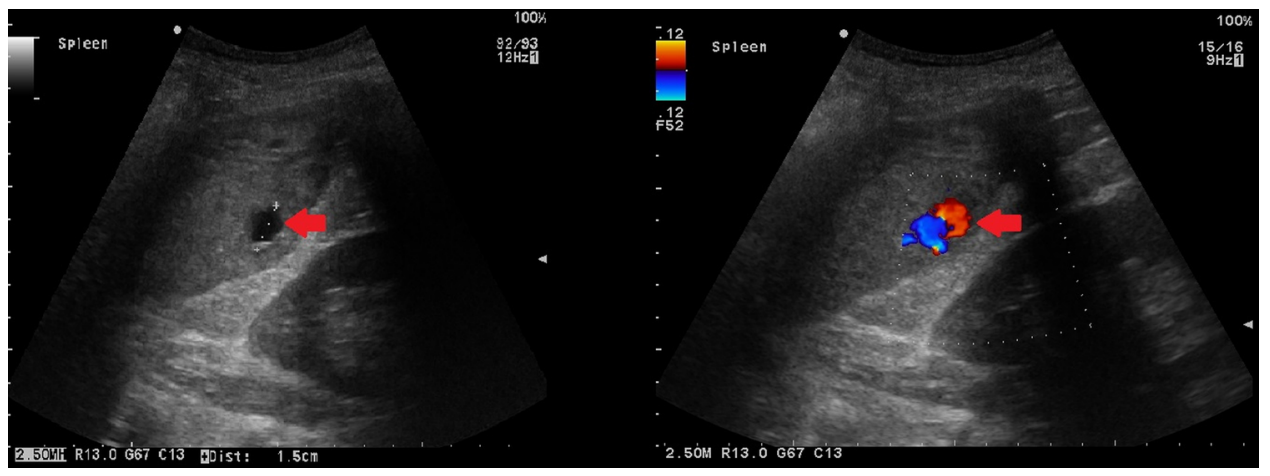

Figure 1 B-mode (left) and Doppler ultrasound (right) demonstrating a hypoechoic lesion in the spleen with bidirectional flow on Doppler examination, or 'Yin-Yang' sign (red arrow) in keeping with an intraparenchymal splenic pseudoaneurysm.

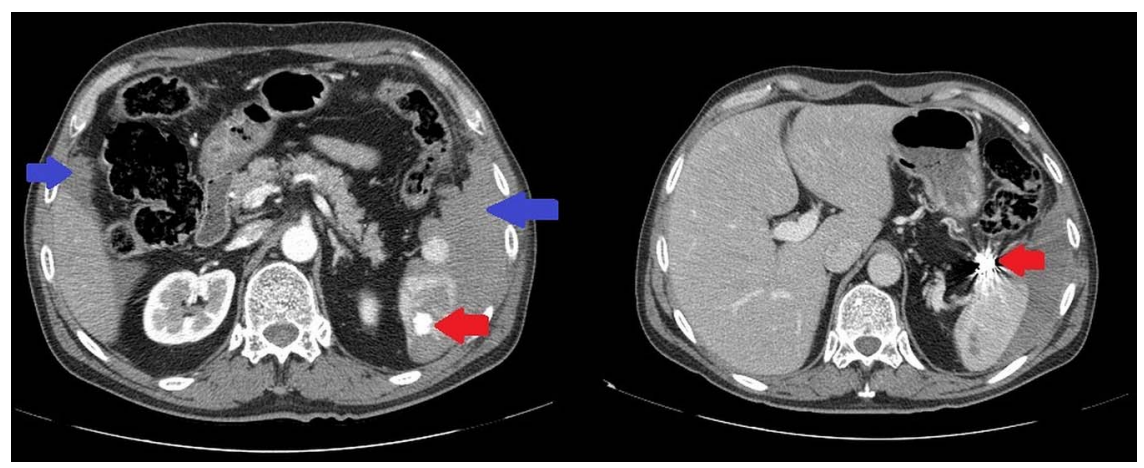

To cite: Azzopardi $\mathrm{C}$, Attard J, Aquilina S, et al. BMJ Case Rep Published online: [please include Day Month Year] doi:10.1136/ bcr-2014-205905

CrossMark

Figure 2 Selected axial images of a contrast-enhanced CT of the abdomen in the arterial phase. On the left, an enhancing $1.5 \mathrm{~cm}$ lesion is seen in keeping with the intraparenchymal splenic pseudoaneurysm (red arrow). On the right, status post-transcatheter embolisation with coils in the feeding vessels of the pseudoaneurysm (red arrow). Peri-splenic and peri-hepatic free fluid is seen (blue arrows). 


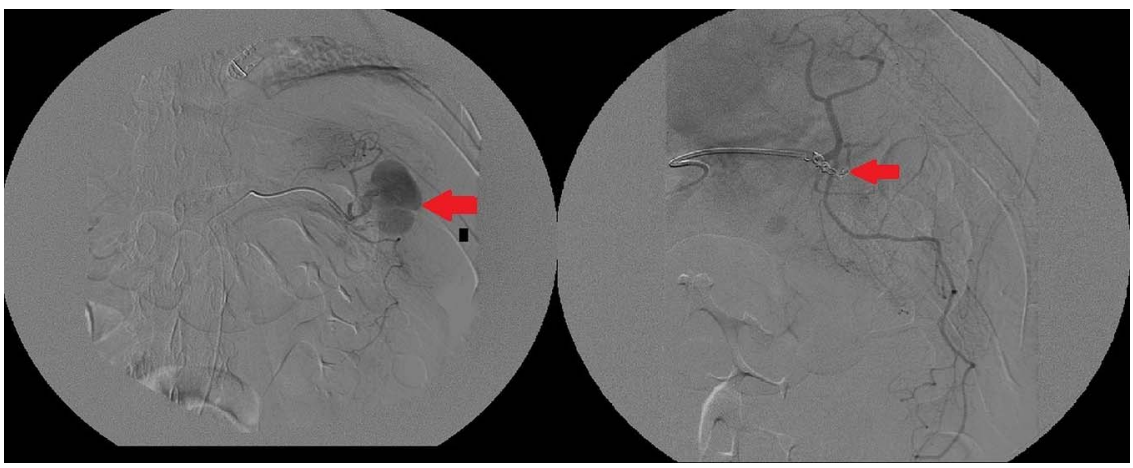

Figure 3 Digital subtraction angiography: on the left, selective splenic arterial angiography with evidence of a contrast blush confirming the pseudoaneurysm (red arrow). On the right, microcoils (red arrow) are visible in the pseudoaneurysm's feeding vessels. The pseudoaneurysm itself is no longer visible.

pseudoaneurysm is as high as $37 \% .^{2}$ Treatment by transcatheter embolisation may avoid the need for surgery and is now becoming the treament of choice in haemodynamically stable patients with blunt splenic injuries. ${ }^{3}$

\section{Learning points}

- Splenic artery pseudoaneurysm is important as a complication of splenic trauma.

- If a patient suffering from a splenic artery pseudoaneurysm becomes unstable, rupture of the said aneurysm is likely and immediate surgical intervention is required.

- Transcatheter embolisation of the pseudoaneurysm is useful in stable patients.
Contributors CA was responsible for conducting the literature review and drafting the manuscript. JA and SA aided in the literature review. RG aided in study supervision and made the radiological diagnosis.

\section{Competing interests None.}

Patient consent Obtained.

Provenance and peer review Not commissioned; externally peer reviewed.

\section{REFERENCES}

1 Hassan R. Computed tomography of blunt spleen injury: a pictorial review. Malays J Med Sci 2011;18:60-7.

2 Agrawal GA. Splenic artery aneurysms and pseudoaneurysms: clinical distinctions and CT appearances. AJR Am J Roentgenol 2007;188:992-9.

3 Shanmuganathan $\mathrm{K}$. Nonsurgical management of blunt splenic injury: use of CT criteria to select patients for splenic arteriography and potential endovascular therapy. Radiology 2000;217:75-82.

Copyright 2014 BMJ Publishing Group. All rights reserved. For permission to reuse any of this content visit http://group.bmi.com/group/rights-licensing/permissions.

BMJ Case Report Fellows may re-use this article for personal use and teaching without any further permission.

Become a Fellow of BMJ Case Reports today and you can:

- Submit as many cases as you like

- Enjoy fast sympathetic peer review and rapid publication of accepted articles

- Access all the published articles

- Re-use any of the published material for personal use and teaching without further permission

For information on Institutional Fellowships contact consortiasales@bmjgroup.com

Visit casereports.bmj.com for more articles like this and to become a Fellow 